\title{
Level of Evidence $\mathrm{V}$
}

National Cancer Institute

\section{Source}

National Cancer Institute. Level of Evidence V. NCI Thesaurus. Code C94652.

Opinion of respected authorities based on clinical experience, descriptive studies, or reports of expert committees. 